\title{
Improving drilling hydraulics estimations-a case study
}

\author{
Rahman Ashena ${ }^{1,2}$ (D) Abdol-Azim Hekmatinia ${ }^{3} \cdot$ Ali Ghalambor $^{4} \cdot$ Bernt Aadnoy $^{5} \cdot$ Charissa Enget $^{6}$. \\ Vamegh Rasouli ${ }^{1}$
}

Received: 11 March 2021 / Accepted: 29 May 2021 / Published online: 17 June 2021

(C) The Author(s) 2021

\begin{abstract}
Accurate pressure drop estimation is important for drill string and bit nozzles design and optimized fluid circulations as well as identifying the drilling problems such as bit nozzle(s) washout or plugging. In this study, the Bingham Plastic model has been modified by applying a coefficient to its turbulent pressure loss calculations. This coefficient encompasses the effects of the drill pipe tool joints and other effects in estimation of pressure losses. The range of the coefficient was determined in field applications for different hole sizes and mud types. The results showed that applying a correction coefficient of 1.08-1.12 to turbulent pressure loss equations (depending on borehole size and mud type) improves the pressure loss estimation. By applying this coefficient, the estimated pressure losses are increased to compensate the under-estimation of the Bingham Plastic model. This is considered a significant contribution to accurate calculation of borehole hydraulics and in-time detection and identification of borehole problems and reduction of invisible lost time. The findings also showed that this enhanced effect is independent of the mud type. The use of this coefficient removes the necessity of using rather complex mud rheological models such as the Herschel-Bulkley model.
\end{abstract}

Keywords Drilling hydraulics $\cdot$ Modified pressure estimation $\cdot$ Updated bingham plastic model $\cdot$ Total pressure loss

\section{Introduction}

The fluid pressure varies widely along the circulation loop including the standpipe, the drill-string, across the bit nozzles and along the annular space. In most drilling operation, single-phase liquid muds are used (as is focused in this work), whereas multiphase fluids such as aerated muds may be used in some specific situations (Guo et al. 2004 and Sun et al. 2006). Accurate hydraulics pressure prediction is of great interest in drilling during the planning phase (hydraulics design) and the execution phase for detection and identification of drilling problems in a real-time manner.

Rahman Ashena

ashena.rahman@gmail.com

1 University of North Dakota, Grand Forks, USA

2 Asia Pacific University of Technology and Innovation (APU), Kuala-Lumpur, Malaysia

3 Ahvaz, Iran

4 Oil Center Research International, Lafayette, USA

5 University of Stavanger, Stavanger, Norway

6 Denver, USA
Accurate hydraulics estimations are greatly important for managed pressure drilling (MPD) systems.

Presenting a simple real case example may clarify the importance of hydraulic pressure prediction in safe and economic drilling operation. Assume that during drilling a 17 $1 / 2$-in hole, the mud logger or the drilling supervisor does not notice a small standpipe pressure (SPP) drop of 60-70 psi (out of SPP of $2900 \mathrm{psi}$ ). The consequence of this could be the pipe twist-off and failure which requires the timely and costly fishing operation to remove it from the wellbore. This incident could be avoided if an automated hydraulic model were in place to monitor the variation in the expected total pressure loss and compare it with the actual SPP. This system is equipped with an alarm system which goes off as soon as the trend of pressure exceeds beyond a certain threshold as an early warning. For instance, under constant fluid rheological and circulation parameters, hydraulics calculations confirm that SPP is expected to increase slightly during drilling due to depth increase. During drilling, any small reduction in SPP will activate the alarm. A change in pressure, depending on magnitude and increase or decrease, is an indication of borehole-associated problems such as bit plugging or washout, tight holes, well control (kick flows), 
mud loss, unrepresentative mud properties, errors in mud logging sensors readings, and cuttings accumulation in deviated holes.

Several sophisticated relations and models to incorporate different hydraulic parameters (e.g., eccentricity or roughness) have been developed recently and incorporated into sophisticated simulators to improve the prediction. However, these simulators require a large amount of processing time. For pressure changes to be caught in-time, adequate estimation speed of around $1 \mathrm{HZ}$ (one estimation per second) is required. This suggests the use of simple relations and models for real-time estimations of automated hydraulics during drilling. Several researchers (Fruhwirth et al. 2006; Zoellner et al. 2011; Wang and Salehi 2015; Shahri et al. 2018) have proposed using artificial intelligence (AI), particularly artificial neural networks (ANN) for hydraulics prediction.

In this work, first, pressure-associated drilling problems and necessary measures to be taken to overcome problems are discussed. The role of accurate hydraulics calculations is considered one of the most important measures. Different sources of errors in hydraulic estimations will be discussed. Using measured field data and data fitting techniques, correction coefficients are developed in different hole sizes, in order to compensate the difference between the actual standpipe pressure and the total system pressure drop.

\section{Pressure-associated drilling problems and hydraulics role}

Most borehole-related problems during drilling affect SPP measurements. In one type of classification, these problems can fall into two categories. In the first category, due to a mechanical failure in the drill string, the mud flow path is either shortened or an impediment is placed against the path causing pressure disruptions. Some examples of this are bit nozzle washout, bit nozzle or drill string plug, and drill string washout and twist-off. These problems affect the SPP directly. The second category of problems is related to wellbore geomechanics (an example work is Ashena et al. 2020), such as kicks and tight holes. These are indirectly related to hydraulics, but they also affect SPP as one of the surface indications.

In another classification, downhole pressure-associated problems are categorized depending on their effect on decrease or increase in the SPP. These are discussed in the following subsections:

\section{Decrease in SPP}

A decrease in SPP may occur in the following cases:

\section{Nozzle(s) washout/lost jet}

If a bit nozzle comes off its port/opening in the bit, jet effect is lost at the nozzle and a decrease in bit pressure drop and SPP occurs. This results in a rate of penetration (ROP) decrease. To calculate the magnitude of the expected pressure drop, first the area of one nozzle is replaced by the area of a full-open port which will result in larger total flow area (TFA). Then, the bit pressure drop is calculated using the larger TFA. Hydraulics calculations can contribute to the detection of the problem. If the magnitude of the calculated pressure drop due to nozzle washout is close to the magnitude of the actual pressure drop, nozzle washout can be inferred. The implication of this is that if nozzle washout is not identified, the drilling rate is adversely affected and cones of rock bits or teeth of the PDC bits are severely damaged. This results in accelerated bit wear and a premature need for a bit change causing a halt in the drilling progress.

\section{Drill string washout and pipe twist-off}

If there exists washout along the drill pipe, depending on the location of the washout, the amount of SPP drop differs. The nearer the washout location to the surface, the shorter the flow path, and the greater the drop in SPP. Conversely, the nearer is the washout spot to the bit, the lesser the pressure drop will be, and the more difficult to notice it. This low pressure drop may be as low as 50 psi depending on the location of the washout. A consequence of failing to detect the washout in a timely manner would be the pipe twisting off, resulting in fishing operation to remove the junk pipe. In this case, in addition to the SPP drop, drilling string weight loss would be experienced. Pipe twist-off is considered a serious borehole problem as it requires fishing operations and a considerable halt in drilling progress.

\section{Opening of already plugged bit nozzles}

Consider a situation where the DPs have been flushed properly following cementing operations. In this case, some flakes or scales may stay and stick to the inner sides of the pipes. If the driller does not conduct a full inspection before running them back in the hole during the next shift, some of these flakes may come off and plug the bit nozzles. If this occurs, the plugging will not be detected by the driller or drilling supervisor (through this should never happen). Depending on the pump flow rate, it is possible that the debris will be removed from the nozzles and plugged nozzles will be unplugged which would indicate a decrease in SPP. Therefore, accurate hydraulics pressure calculations will allow detecting both nozzle plugging and unplugging. 


\section{Mud loss}

If a severe mud loss occurs, SPP decreases. The magnitude of the pressure drop is obtained by replacing the new circulation rate in the annulus. The new circulation rate is calculated by subtracting the rate of mud volume loss from the circulation rate and recalculating the annular pressure drop.

\section{Kick flow}

When a kick flow occurs, a minimal reduction in SPP and a minimal increase in pump flow rate occur as a secondary indication. These are attributed to the contribution of the kicking formation pressure to fluid displacement. Therefore, improving the accuracy of hydraulics calculations in this work contributes to detection of possible discrepancies and kick flows.

\section{Increase in SPP}

\section{Nozzle(s) plug}

During drilling, one or several bit nozzles may become plugged. The plugging material can come from lost circulation materials (LCMs) in case of pumping LCM pills, possible barite sag or settling of weighting materials, or the cement flakes from the cement scales (which may come off from the inner side of the DPs). If nozzle(s) are plugged, depending on the number and size of the plugged nozzles, SPP will increase suddenly. This sudden increase is usually detected by the driller or supervisor, but any delay in detection may consequently lead to washout of the pin of the bit or even the drill string. In severe cases, the bit may cut at its pin and fish down the hole. To calculate the magnitude of the increase, simply eliminate the area of the nozzle(s) from the TFA. As for the implication, in case the detection of the problem is not made in time, it could lead to poor hydraulics and hole cleaning, bit balling of the bit (on the side of plugged nozzles), or a drop in ROP.

\section{Tight borehole}

Tight borehole regions may exist in the open-hole annulus. These can be present in drilling marl or shale-bearing formations which are accompanied with high drilling torque. In these cases, SPP may increase.

In case of observing standpipe pressure (SPP) changes, a method of identifying the problem, hydraulics calculations are performed to find the total or system pressure loss and compare it with the actual SPP. Accuracy of hydraulics calculations is significantly important. If the pressure drop is considerable (say $500 \mathrm{psi}$ ), it may be due to nozzle(s) washout. If a pressure drop occurs along with a loss of the drill string weight, the drill string is twisted-off and a pipe fish is in the hole. If pressure drop is rather small (say 50-200 psi), it may be the drill string washout. If a significant pressure increase is observed, it may be due to nozzle plugging. If a small increase in SPP is observed, it may be due to tight holes. Therefore, dummy trips or wash-and-reams may be attempted to remove the tight hole, which makes the SPP back to normal.

Due to the important role of hydraulics in pressure-associated drilling problems, two issues are important. First, it is suggested that the mud logging units be equipped with an accurate hydraulics estimation of system pressure loss to compare it with the actual SPP in real time. Therefore, in an emergency, the drilling supervisors do not need to do the time-consuming calculations by themselves. Second, guaranteeing high accuracy of hydraulics calculations is important for proper identification of problems which is discussed in the rest of this paper.

\section{Improving accuracy of hydraulics calculations}

\section{Sources of errors}

There are several sources of errors in conventional hydraulics calculations which are discussed as follows:

\section{Tool joints}

Tool joints have smaller inside diameters (IDs) than the pipe body. This causes some restriction against flow in pipes with contraction and expansion of the fluid as it enters and exits (Jeong and Shah 2004). This effect is considerable as fluid velocity in the string is high and flow pattern is turbulent. They have also larger outside diameters (ODs) than the pipe body. Therefore, the annulus clearance across a tool joint is smaller than the annulus clearance across the pipe body which creates some restriction against flow. However, the effect is minimal because fluid velocity is so low in the annulus.

In addition, partial diversion of fluid flow occurs at tool joints, which means that the direction of part of the stream is altered. Both of these effects alter the characteristic flow pattern and create further turbulence or elevation of the turbulent friction factor (White et al. 1996). Therefore, existence of tool joints causes extra pressure losses in the drill pipes and their annuli. Since drill collars do not have tool joints and their inside diameter is usually constant, this effect does not apply to them. The API recommended RP 13D (2003) for drilling hydraulics calculation techniques does not include the tool joint effect (Ochoa 2006). The API RP 13D (2009) just cited some recent research works (White

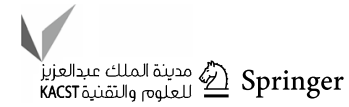


et al. 1996 and Jeong and Shah 2004), but did not mention the equations in detail. Some researchers have theoretically modeled this and experimentally investigated or developed empirical correlations (Denison 1977; Mccain 1994; Jeong and Shah 2004; Simoes 2005; Ochoa 2006; Calcada et al. 2012). Various bit manufacturing companies use some of these models. Ignoring the "tool joint effect" causes considerable error in pressure loss calculations. It affects both the pressure drops in the drill pipe and in the annulus.

\section{Ignoring pipe roughness}

Owing to the chaotic nature of fluid particle movement in turbulent flow, it is extremely difficult to arrive at an exact analytical method for determining pressure losses (Rabia 1985). To resolve the issue, simplification of friction factor equation is essential.

Blasius equation is a simple equation commonly used in drilling sources to find the Darcy friction factor in turbulent pressure drop (see Blasius 1913), and this was later used and cited by Schlumberger (1984); Rabia (1985), and Moore (1986). This equation is popular as it only depends on the Reynolds number and is independent of roughness. This equation was originally derived from Navier-Stokes equations for Newtonian fluids, and its coefficients were found using researchers' experiments. Different researchers used different coefficients for the equations (Rabia 1985; Moore 1986; Kelessidis and Bandelis 2004; Guo and Liu 2011, see Table 5 in Appendix) which is therefore considered an uncertainty in the equation. Using the effective viscosity concept, the equation is applicable to non-Newtonian fluids (Weltmann 1956). Another equation recommended by API (2009) for finding the turbulent friction factor is Churchill (1977) which is similar to Blasius (1913), independent of roughness.

As the Blasius equation ignores pipe roughness, it is only proposed for the calculation of pressure drop in smooth pipes. Drill pipes are sometimes rather old and have rough interior surfaces. Therefore, the common use of Blasius equation in hydraulics equations in turbulent flow is considered a source of error (White et al. 1996). API (2009) and Bourgoyne et al. (1991) generally suggested that ignoring the roughness does not cause significant errors, whereas White et al. (1996) mention noticeable effect of the roughness even for plastic-coated pipes.

\section{Assumption about effective viscosity in turbulent flow}

The Blasius equation includes a term for the Reynolds number. The Reynolds number is found by multiplying the mud density, velocity, and hydraulic diameter and dividing by the effective viscosity. In turbulent flow, it is assumed that the effective viscosity is equal to the plastic viscosity (PV) divided by 3.2 (Rabia 1985 and Moore 1986, p. 256).
Therefore, plastic viscosity enters the Blasius equation through the Reynolds number. This is an assumption which may not be necessarily correct.

\section{Critical Reynolds number}

There is a discrepancy in researchers' opinions on the value of the critical Reynolds number. Some researchers such as Moore (1986) considered the value of 2000 as the critical number, whereas in drilling mostly the value of 3000 is considered (Rabia, 1985), but these are all empirical values.

\section{Temperature and pressure effects on mud rheology}

During drilling, the drilling mud is subjected to its own hydrostatic pressure and formation temperature. Mud properties are typically measured at ambient pressure and a lower temperature than the hole, including the rheological parameters (plastic viscosity PV, yield point YP, gel strength GS, and mud weight MW) which are directly used in hydraulics calculations. The pressure and temperature differences between the hole and the surface are considerable, particularly in HPHT wells and at low circulation rates (Osisanya and Harris 2005).

Higher bottomhole temperature causes mud expansion which lowers mud weight and rheological parameters (White et al. 1996). Conversely, greater bottomhole pressure causes slight fluid compression and increases the aforementioned parameters. These two conflicting effects almost cancel out in oil-based muds in vertical wells. However, in water-based muds, the temperature effect is much larger than the pressure effect (Rommetveit and Bjorkevoll 1997; Patel and Chaudhari 2014). To consider these effects, it is required to accurately know the pressure and temperature dependence of the density, viscosity, and gel strength of the actual mud system as well as the temperature profile in the well. These effects are not considered in normal hydraulics calculations and are considered a source of error, particularly in HPHT wells.

\section{Rotation and eccentricity effects}

A number of studies were done on the effect of drill string rotation on annular pressure drop (APL) and equivalent circulating density (ECD) (Walker and Al-Rawi 1970; Luo and Peden 1987; Bailey and Peden 2000, Ooms et al. 1999; and Ravi and Hemphill 2006). Rotation is known to lower APL and ECD at low rotation speeds and increase APL beyond a certain rotation speed (Ravi and Hemphill, 2006). The model proving this was presented in Hemphil et al. (2008). In inclined boreholes, drill strings are eccentric in the hole and pipe rotation has some effect on that. Eccentricity also causes the reduction of annular pressure loss in laminar and turbulent flow. A model of the effect of eccentricity on hydraulic pressures was proposed by Haciislamoglu (1994) which is also 
cited in the API RP $13 D$ (2009). A more recent model was given by Zamora et al. (2005). However, relationships that consider the combined effects of pipe rotation, and eccentricity and drill string instabilities (API 2009) are not readily available, although some works involving these were done by Ravi and Hemphill (2006).

\section{Discharge coefficient $\left(C_{d}\right)$}

The actual mud exit velocity out of bit nozzles is lower than the calculated values by conventional equations. This is attributed to frictional losses and an eddy in the nozzles. To account for this, a correction factor called discharge coefficient $\left(\mathrm{C}_{\mathrm{d}}\right)$ was introduced. The value of $C_{d}$ was experimentally found to range up to 0.99 depending on the shape and design of nozzles and the back-pressure on the nozzles (Eckel and Bielstein 1951; Kristler 1953). However, the value of 0.95 is used by most publications though some practitioners recommend 0.98 . As a source of error, " 0.95 " may not necessarily be the exact value of $\mathrm{C}_{\mathrm{d}}$ for nozzles used in a specified drilling job. The exact results must be experimentally found.

\section{Cuttings}

Cuttings are generated at the bit face and are transported to the surface by the mud through the annulus. This means a greater mud weight exists in the annulus which causes greater APL than what is calculated. The greater the ROP, the greater the generated cuttings, the mud weight in the annulus, and the APL. The effect of cuttings is more in deviated and slim-hole wells (API 2009).

\section{Laminar pressure estimation errors}

In laminar flow regime, some pressure drop occurs. Several models such as the Power Law and the Bingham Plastic are used to estimate pressure drops in the laminar regime. The Herschel-Bulkley model is considered a more accurate and accepted model for the calculation of oil-well drilling fluid rheology and hydraulics (Klotz and Brigham 1998; Bern et al. 2006). This is because it accommodates the existence of a yield point as well as the nonlinearity of the relationship of shear stress to shear rate (Power and Zamora 2003). However, this equation is complex since it includes iterative methods. Therefore, most drilling companies and rigs still prefer to use simpler models, particularly the Bingham Plastic model.

\section{Correction coefficients and data fitting}

Most of the errors in hydraulics calculations are attributed to the turbulent flow regime, particularly in the drill string. This has been confirmed experimentally, but it can be accounted for theoretically. Using downhole pressure and temperature sensors in the drill string and annulus, White et al. (1996) found that actual drill string pressures (turbulent) are significantly higher than predicted by API equations which accounts for discrepancies between the actual SPP and estimated total pressure losses using rheological models. The theoretical reasons for this observation are given as follows:

\section{Simplified turbulent flow equations}

Due to the assumptions and simplified equations presented in the previous section to calculate pressure drop (e.g., Blasius equation), the possibility of error is greater in the turbulent flow than that of the laminar flow regime. However, possible error in the laminar flow regime is low since equations are based on robust analytical equations with few assumptions. Similarly, possibility of error in the calculation of bit nozzle pressure drop is limited as their pressure drop calculations are rather accurate and nozzles are very short in length.

\section{Higher velocities and pressure drops in turbulent flow}

Due to low velocities in laminar regime, laminar pressure losses are minimal. Because of higher velocities in the drill string, most of the system pressure loss occurs where the turbulent flow exists. Generally, the deviation from the actual value (error) is more where there are greater pressure magnitudes (i.e., turbulent regime). Therefore, the tool joint effect is much more considerable inside the drill string compared to the annulus.

Assuming the mud weight/density in the annulus is the same as the drill string, the total pressure drop in a mud circulation system is estimated as follows:

$\Delta P_{\text {total }}=\Delta P_{\text {surf }}+\Delta P_{\text {bit }}+\sum \Delta P_{\text {lam }}+\sum \Delta P_{\text {turb }}$

where $\Delta P_{\text {surf }}$ is the pressure drop in the surface lines; $\Delta P_{b i t}$ is the bit pressure drop; $\sum \Delta P_{\text {lam }}$ is the sum of the laminar pressure drops (which can be found using either Bingham Plastic or Power Law model); and $\sum \Delta P_{\text {turb }}$ is the sum of the turbulent pressure drops in the drill string.

Considering the parameters of Eq. 1, it is assumed that the discrepancy between the estimated total pressure drop and the actual SPP is mainly related to the turbulent pressure drops in the drill string. Regardless of the correctness of this assumption, a correction coefficient called $C_{t}$ is multiplied by pressure drops in turbulent regimes in the drill string with the objective of compensating the mentioned discrepancy. In fact, the turbulence correction coefficient $\left(\mathrm{C}_{\mathrm{t}}\right)$ considers the errors in the turbulence flow regime as well as the other errors in the laminar regime and the bit nozzles. In other words, this coefficient will cover all possible sources of errors.

The corrected total pressure drop estimated in Bingham Plastic model $\left(\Delta P_{\text {total.Bing, },}\right)$ is found by incorporating the 
Table 1 Input data used for hydraulics calculation for several cases in the $8 \frac{1}{2} 2$-in borehole.

\begin{tabular}{|c|c|c|c|c|c|c|c|c|c|}
\hline Case & Depth & Drill pipe length [in] & $\begin{array}{l}\text { Mud } \\
\text { weight } \\
{[\mathrm{ppg}]}\end{array}$ & $\begin{array}{l}\text { Plastic } \\
\text { viscosity, PV } \\
{[\mathrm{cp}]}\end{array}$ & $\begin{array}{l}\text { Yield point } \\
{\left[\mathrm{Ibf} / 100 \mathrm{ft}^{2}\right]}\end{array}$ & $\begin{array}{l}\text { Noz- } \\
\text { zle size } \\
{[1 / 32 \text { in }]}\end{array}$ & $\begin{array}{l}\text { Circulation rate } \\
\text { [Gallon/min] }\end{array}$ & $\begin{array}{l}\text { Down- } \\
\text { hole } \\
\text { motor }\end{array}$ & SPP [psi] \\
\hline 1 & $3,104 \mathrm{~m} / 10,184 \mathrm{ft}$ & $2,674 \mathrm{~m} / 8,773 \mathrm{ft}$ & 10.6 & 32 & 11 & $3 \times 20$ & 490 & Yes & 2700 \\
\hline 2 & $2,485 \mathrm{~m} / 8,153 \mathrm{ft}$ & $2,297 \mathrm{~m} / 7,536 \mathrm{ft}$ & 9.9 & 8 & 6 & $3 \times 32$ & 300 & No & 400 \\
\hline 3 & $2,566 \mathrm{~m} / 8,419 \mathrm{ft}$ & $2,378 \mathrm{~m} / 7,802 \mathrm{ft}$ & 9.89 & 9 & 8 & $3 \times 32$ & 300 & No & 500 \\
\hline 4 & $3,305 \mathrm{~m} 10,844 \mathrm{ft}$ & $3,129 \mathrm{~m} / 10,266 \mathrm{ft}$ & 9.9 & 24 & 10 & $3 \times 32$ & 330 & No & 735 \\
\hline 5 & $2,806 \mathrm{~m} / 9,206 \mathrm{ft}$ & $2,633 \mathrm{~m} / 8,639 \mathrm{ft}$ & 9.63 & 22 & 9 & $3 \times 16$ & 470 & No & 1900 \\
\hline 6 & $2,854 \mathrm{~m} / 9,364 \mathrm{ft}$ & $2,701 \mathrm{~m} / 8,862 \mathrm{ft}$ & 8.96 & 25 & 12 & $7 \times 32$ & 250 & No & 420 \\
\hline 7 & $3,022 \mathrm{~m} / 9,915 \mathrm{ft}$ & $2,870 \mathrm{~m} / 9,416 \mathrm{ft}$ & 8.96 & 5 & 11 & $7 \times 32$ & 290 & No & 400 \\
\hline 8 & $3,178 \mathrm{~m} / 10,427 \mathrm{ft}$ & $3,025 \mathrm{~m} / 9,925 \mathrm{ft}$ & 8.96 & 32 & 14 & $7 \times 32$ & 255 & No & 590 \\
\hline 9 & $2,937 \mathrm{~m} / 9,636 \mathrm{ft}$ & $2,683 \mathrm{~m} / 8,803 \mathrm{ft}$ & $19.6^{*}$ & 56 & 19 & $3 \times 32$ & 238 & No & 930 \\
\hline 10 & $1,771 \mathrm{~m} / 5,810 \mathrm{ft}$ & $1,620 \mathrm{~m} / 5,315 \mathrm{ft}$ & 8.82 & 5 & 13 & $6 \times 14$ & 450 & No & 700 \\
\hline 11 & $1,804 \mathrm{~m} / 5,919 \mathrm{ft}$ & $1,653 \mathrm{~m} / 5,423 \mathrm{ft}$ & 8.82 & 5 & 12 & $6 \times 14$ & 450 & No & 700 \\
\hline 12 & $1,851 \mathrm{~m} / 6,073 \mathrm{ft}$ & $1,700 \mathrm{~m} / 5,577 \mathrm{ft}$ & 8.82 & 5 & 12 & $6 \times 14$ & 450 & No & 710 \\
\hline 13 & $1,922 \mathrm{~m} / 6,306 \mathrm{ft}$ & $1,771 \mathrm{~m} / 5,810 \mathrm{ft}$ & 8.82 & 5 & 12 & $6 \times 14$ & 450 & No & 720 \\
\hline 14 & $1,947 \mathrm{~m} / 6,388 \mathrm{ft}$ & $1,796 \mathrm{~m} / 5,893 \mathrm{ft}$ & 8.82 & 5 & 13 & $6 \times 14$ & 450 & No & 705 \\
\hline 15 & $3,370 \mathrm{~m} / 11,057 \mathrm{ft}$ & $3,192 \mathrm{~m} / 10,473 \mathrm{ft}$ & 9.22 & 18 & 11 & $3 \times 16$ & 400 & No & 1500 \\
\hline
\end{tabular}

It is noted that the drill pipe outside diameter was 5 in and the drill collars outside diameter was $61 / 2$ in

*The mud weight used in this case was exceptionally super-high (19.6 ppg)

Table 2 Explanatory calculation of correction coefficient $\left(C_{t}\right)$ for the cases in the $8 \frac{1}{1 / 2}$-in borehole size

\begin{tabular}{lllllllll}
\hline Case & $\begin{array}{l}\text { Total pressure } \\
\text { loss (measured) }\end{array}$ & Surf. lines & Bit & Laminar & Turb & Difference (Final) & Least square (Final) & Correction coefficient \\
& $S P P$ & $\Delta P_{\text {surf }}$ & $\Delta P_{\text {bit }}$ & $\Delta P_{\text {lam, Bing }}$ & $\Delta P_{\text {turb }}$ & $\delta$ & L.S & $\mathrm{C}_{\mathrm{t}}$ \\
& & & & & & $($ Eq. 4) & (Eq. 5) \\
\hline 1 & 2700 & 39 & 275 & 319 & 2011 & 130.54 & $1.70 \mathrm{E}+04$ & $1.092 \sim 1.1$ \\
2 & 400 & 12 & 15 & 78 & 266 & 4.78 & $2.29 \mathrm{E}+01$ & $3.99 \mathrm{E}+03$ \\
3 & 500 & 12 & 15 & 110 & 274 & 63.18 & $1.89 \mathrm{E}+02$ \\
4 & 735 & 17 & 5 & 213 & 470 & 13.74 & $4.36 \mathrm{E}+04$ \\
5 & 1900 & 30 & 565 & 165 & 852 & 208.87 & $3.47 \mathrm{E}+02$ \\
6 & 420 & 10 & 2 & 357 & 64 & 18.63 & $7.25 \mathrm{E}+02$ \\
7 & 400 & 10 & 2 & 164 & 230 & 26.92 & $5.04 \mathrm{E}+02$ \\
8 & 590 & 10 & 2 & 479 & 70 & 22.46 & $6.60 \mathrm{E}+03$ \\
9 & 930 & 18 & 20 & 620 & 175 & 81.26 & $2.16 \mathrm{E}+02$ \\
10 & 700 & 20 & 202 & 101 & 358 & 14.69 & $1.99 \mathrm{E}+02$ \\
11 & 700 & 20 & 202 & 97 & 362 & 14.10 & $1.85 \mathrm{E}+02$ \\
12 & 710 & 20 & 202 & 99 & 368 & 13.60 & $3.22 \mathrm{E}+02$ \\
13 & 720 & 20 & 202 & 104 & 377 & 17.94 & $2.12 \mathrm{E}+03$ \\
14 & 705 & 20 & 202 & 113 & 381 & 46.04 & $2.71 \mathrm{E}+04$ \\
15 & 1500 & 21 & 392 & 234 & 630 & 164.69 &
\end{tabular}

The data were gathered from seven wells. The word "Final" indicates that all the iterations were done, and good data fitting was achieved

*Existence of a downhole motor and measurement while drilling (MWD) system caused the pressure drop of 850 psi in the system. This value was added to the total pressure drop

multiplier $C_{t}$ to update the sum of turbulent pressure drops $\left(C_{t} \times \sum \Delta P_{\text {turb }}\right)$ :

$$
\Delta P_{\text {total.Bing }, c}=\Delta P_{\text {surf }}+\Delta P_{\text {bit }}+\sum \Delta P_{\text {lam.Bing }}+C_{t} \times \sum \Delta P_{\text {turb }}
$$


Table 3 Comparison of estimated total pressure drops with the actual standpipe pressure (SPP) and calculation of errors in average absolute percent errors (AAPEs) and least square (L.S.) and mean square errors (MSEs).

\begin{tabular}{|c|c|c|c|c|c|c|c|c|c|c|}
\hline \multirow[t]{3}{*}{ Case } & \multicolumn{4}{|l|}{ Total } & \multicolumn{6}{|l|}{ Errors } \\
\hline & \multicolumn{3}{|l|}{ (Estimated) } & \multirow{2}{*}{$\begin{array}{l}\text { (Actual) } \\
\text { SPP }\end{array}$} & \multicolumn{3}{|c|}{ AAPE $\%$} & \multicolumn{3}{|c|}{ Least Square (L.S.) } \\
\hline & $\begin{array}{l}\Delta P_{\text {total,Power }} \\
\text { (Eq. 1) }\end{array}$ & $\begin{array}{l}\Delta P_{\text {total,Bing }} \\
\text { (Eq. 1) }\end{array}$ & $\begin{array}{l}\Delta P_{\text {total.Bing, },} \\
\text { (Eq. 2) }\end{array}$ & & $\begin{array}{l}\text { Power } \\
\text { (Eq. 7) }\end{array}$ & Bing & Corrected-Bing & $\begin{array}{l}\text { Power } \\
\text { (Eq. 5) }\end{array}$ & Bing & Corrected-Bing \\
\hline 1 & 2559 & 2644 & 2831 & 2700 & 5.22 & 2.07 & 4.83 & $1.99 \mathrm{E}+04$ & $3.13 \mathrm{E}+03$ & $1.70 \mathrm{E}+04$ \\
\hline 2 & 332 & 371 & 395 & 400 & 17.08 & 7.36 & 1.20 & $4.66 \mathrm{E}+03$ & $8.67 \mathrm{E}+02$ & $2.29 \mathrm{E}+01$ \\
\hline 3 & 358 & 411 & 437 & 500 & 28.36 & 17.72 & 12.64 & $2.01 \mathrm{E}+04$ & $7.85 \mathrm{E}+03$ & $3.99 \mathrm{E}+03$ \\
\hline 4 & 612 & 705 & 749 & 735 & 16.75 & 4.06 & 1.87 & $1.52 \mathrm{E}+04$ & $8.92 \mathrm{E}+02$ & $1.89 \mathrm{E}+02$ \\
\hline 5 & 1554 & 1612 & 1691 & 1900 & 18.22 & 15.15 & 10.99 & $1.20 \mathrm{E}+05$ & $8.29 \mathrm{E}+04$ & $4.36 \mathrm{E}+04$ \\
\hline 6 & 270 & 433 & 439 & 420 & 35.82 & 3.02 & 4.43 & $2.26 \mathrm{E}+04$ & $1.61 \mathrm{E}+02$ & $3.47 \mathrm{E}+02$ \\
\hline 7 & 335 & 406 & 427 & 400 & 16.20 & 1.41 & 6.73 & $4.20 \mathrm{E}+03$ & $3.17 \mathrm{E}+01$ & $7.25 \mathrm{E}+02$ \\
\hline 8 & 347 & 561 & 568 & 590 & 41.14 & 4.90 & 3.81 & $5.89 \mathrm{E}+04$ & $8.36 \mathrm{E}+02$ & $5.04 \mathrm{E}+02$ \\
\hline 9 & 552 & 833 & 849 & 930 & 40.65 & 10.48 & 8.74 & $1.43 \mathrm{E}+05$ & $9.50 \mathrm{E}+03$ & $6.60 \mathrm{E}+03$ \\
\hline 10 & 646 & 681 & 715 & 700 & 7.74 & 2.64 & 2.10 & $2.93 \mathrm{E}+03$ & $3.43 \mathrm{E}+02$ & $2.16 \mathrm{E}+02$ \\
\hline 11 & 646 & 681 & 714 & 700 & 7.68 & 2.78 & 2.01 & $2.89 \mathrm{E}+03$ & $3.80 \mathrm{E}+02$ & $1.99 \mathrm{E}+02$ \\
\hline 12 & 654 & 689 & 724 & 710 & 7.86 & 2.89 & 1.92 & $3.12 \mathrm{E}+03$ & $4.22 \mathrm{E}+02$ & $1.85 \mathrm{E}+02$ \\
\hline 13 & 666 & 703 & 738 & 720 & 7.47 & 2.37 & 2.49 & $2.90 \mathrm{E}+03$ & $2.91 \mathrm{E}+02$ & $3.22 \mathrm{E}+02$ \\
\hline 14 & 676 & 716 & 751 & 705 & 4.08 & 1.52 & 6.53 & $8.28 \mathrm{E}+02$ & $1.16 \mathrm{E}+02$ & $2.12 \mathrm{E}+03$ \\
\hline 15 & 1186 & 1277 & 1335 & 1500 & 20.97 & 14.87 & 10.98 & $9.89 \mathrm{E}+04$ & $4.98 \mathrm{E}+04$ & $2.71 \mathrm{E}+04$ \\
\hline \multicolumn{5}{|c|}{ Average error: } & 18.35 & 6.22 & 5.42 & $\begin{array}{l}3.47 \mathrm{E}+04 \\
\text { (MSE, Eq. 6) }\end{array}$ & $1.05 \mathrm{E}+04$ & $6.88 \mathrm{E}+03$ \\
\hline
\end{tabular}

In most cases, the Corrected Bingham model shows to have the least errors compared with the other models; in some few cases, its error is not the least because of the nature of regression and the regressed $C_{t}$

By adding this coefficient, it is expected that the corrected total pressure drop tends to the actual SPP:

$\Delta P_{\text {total. Bing, }, c} \cong S P P$.

To find an optimal $C_{t}$ in practical sense, a least square regression or data fitting method was carried out using field measurements from fields in southwest Iran. To do this, first, 54 datasets were gathered from different borehole sizes of 14 onshore vertical wells. Data quality control and filtering was performed in order to ensure that the input data to the model are reliable. The input parameters consisted of hole size, drill string depth, drill collar (DC) diameters and lengths, drill pipe (DP) diameters and lengths, casing size and depth, mud properties, circulation rate, bit nozzles number and sizes, and the actual SPP (which represents the total system pressure loss). They were classified based on the borehole sizes wherein the measurements were made. In particular, it is important that the rheological parameters are carefully measured at the time of the recording the data (Ugochukwu 2015). Also, it was ensured that data were not taken when mud losses were occurring.

Next, the total system pressure drops were found by using the Power Law and the Bingham Plastic model. The model errors were calculated in two formats: using the average absolute percent error (AAPE) and mean square error (MSE). Then, as the innovation in this work, measured datasets were used to tune the Bingham Plastic model by multiplying an optimized correction coefficient $C_{t}$ by its turbulent pressure drops and then finding the total system pressure drop (Equation-1). An optimized value of the target $C_{t}$ was found by applying the ordinary least square (OLS) regression method to the data to minimize the mean square error (MSE). To do this, first an initial (guess) value is given for $C_{t}$ in equation-2 (e.g., value of " 1 "). Next, considering equation-3, the difference $\delta$ is found for each case ( $i$ ) as follows:

$\delta_{i}=\left[\left(S P P-\Delta P_{\text {surf }}-\Delta P_{\text {bit }}-\sum \Delta P_{\text {lam.Bing }}\right)-C_{t} \times \sum \Delta P_{\text {turb }}\right]_{i}$.

Using $\delta$, the least square (L.S.) for each case is found as:

L.S. $._{i}=\delta_{i}^{2}$.

Next, the mean square error (MSE) is found for all the data as: 
Fig. 1 Average absolute percent errors (AAPEs) of predicted total pressure drops from actual standpipe pressures for different cases in $171 / 2$-in hole. The optimized value of the correction coefficient $\mathrm{C}_{\mathrm{t}}$ is 1.094
17 1/2-in Hole $\left(C_{t}=1.094\right)$

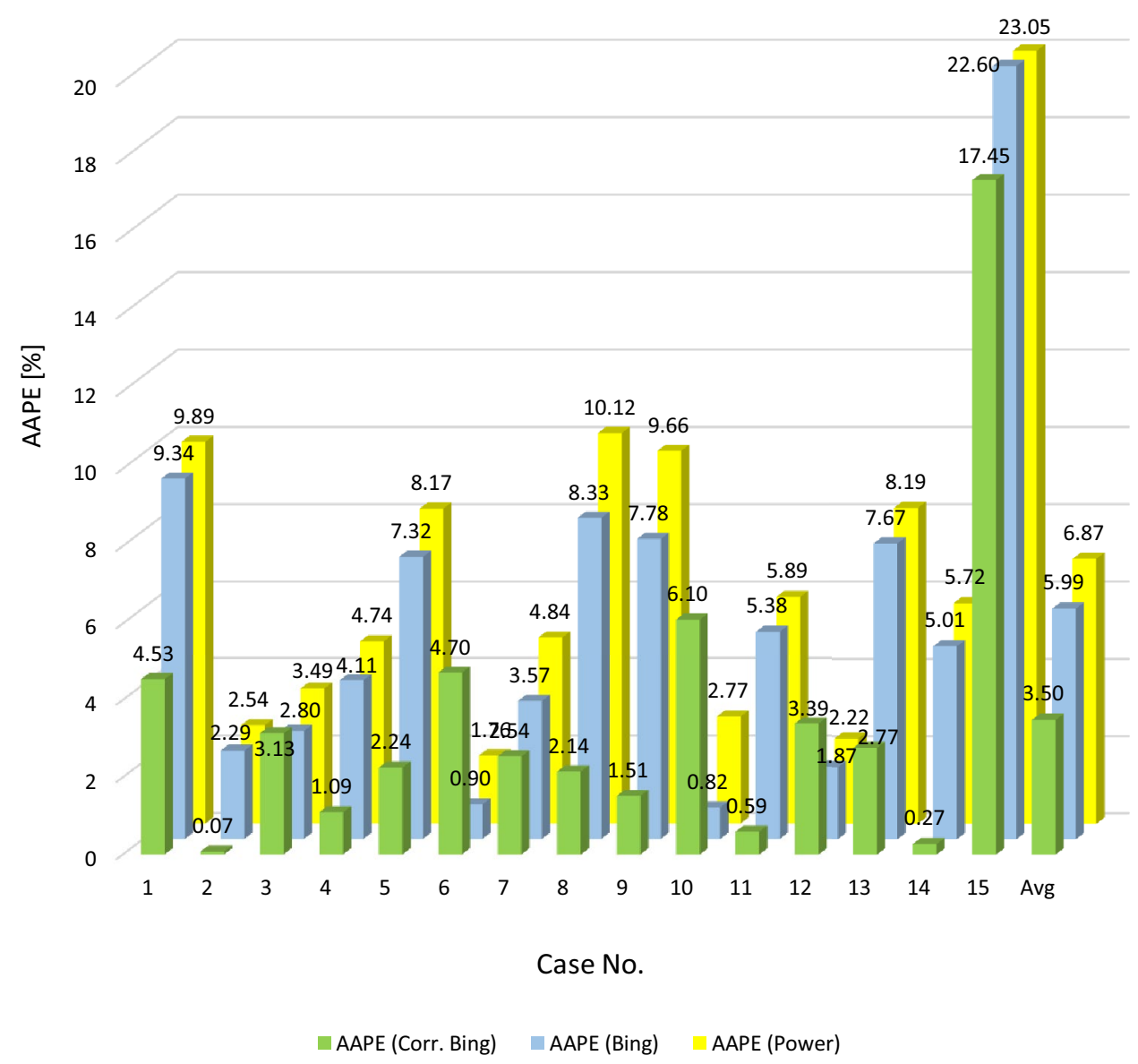

$\mathrm{MSE}=\frac{\sum_{1}^{n} L \cdot S_{\cdot}}{n}$

where $\mathrm{n}$ is the number of cases. This error is considered the main criterion of data fitting in this work.

The regression is continued in an iterative manner such that MSE is minimized. After several iterations, the regressed $C_{t}$ is found when the minimum possible MSE is obtained. The above process was done first using measured data for each borehole size separately and then using combined data of all borehole sizes. Finally, optimized values of $\mathrm{C}_{\mathrm{t}}$ were compared with each other including the case of all combined borehole sizes. It is noted that the reason to find $\mathrm{C}_{\mathrm{t}}$ for each borehole size separately was to consider the possible effect of different geometries of different hole sizes on errors and the correction coefficient.

It is noted that the error can be also calculated using the average absolute percent error (AAPE) as follows:
$\operatorname{AAPE}(\%)=\left|\frac{\mathrm{SSP}-\Delta P_{\text {total }}}{\mathrm{SSP}}\right| \times 100$

where $\Delta P_{\text {total }}$ is the total pressure drops by using either estimation method (the Power Law, the Bingham Plastic, or Corrected Bingham Plastic model).

\section{Results and discussion}

\section{Data fitting}

To explain the data fitting method, first the required input data for one of the borehole sizes $\left(8 \frac{1}{2}\right.$ in) are given in Table 1 . Table 2 shows the steps of the least square regression to find the correction coefficient $\left(\mathrm{C}_{\mathrm{t}}\right)$.

Table 3 lists and compares the total pressure drops and their errors using the different models of Power Law, Bingham Plastic and Corrected Bingham Plastic. Similarly, Figs. 1, 
Fig. 2 AAPEs of predicted total pressure drops from actual standpipe pressures for different

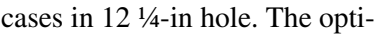
mized value of the correction coefficient $C_{t}$ is 1.12
12 1/4-in Hole $\left(C_{t}=1.12\right)$

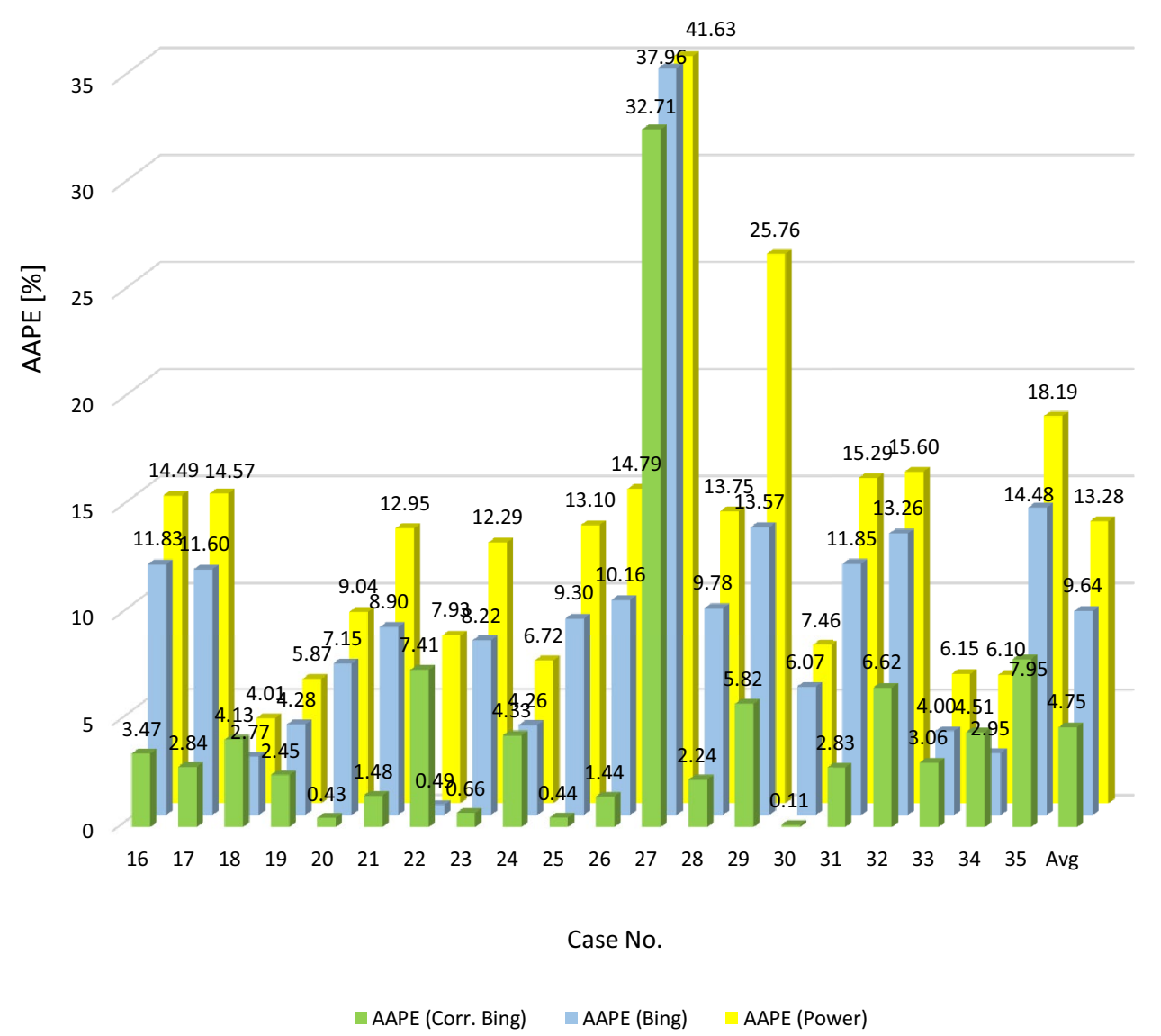

2, 3, and 4 display the performance of the different models in different borehole sizes (respectively, $17 \frac{1}{2} \mathrm{in}, 121 / 4 \mathrm{in}, 8$ $1 / 2$ in, and $61 / 8 \mathrm{in} / 57 / 8$ in) by comparing their errors using the AAPEs. For the $171 / 2$-in borehole, Fig. 1 shows that the Corrected Bingham has the best prediction performance with $3.5 \%$ error. In Case 15, a considerable error of $17.45 \%$ occurred probably because of inaccurate field measurements

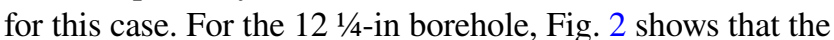
Corrected Bingham has the best prediction performance with 4.75\% AAPE. In Case 27, a considerable error of $32.71 \%$ occurred probably because of inaccuracy in the field measurements. For the $81 \frac{1}{2}$-in borehole, Fig. 3 shows that the Corrected Bingham has the best prediction performance with 5.42\% AAPE. For the $61 / 8$ - and 5 7/8-in boreholes, Fig. 4 shows that the Corrected Bingham has the best prediction performance with $6.8 \%$ AAPE.

The optimized values of $C_{t}$ were found in each borehole size using data fitting performed with the OLS method. Using Figs. 1, 2, 3, and 4, the $C_{t}$ values are 1.094 (17 1/2-in hole), 1.120 (12 1/4-in hole), 1.092 ( $81 \frac{1}{2}$-in hole), and 1.085 (6 1/25and $57 / 8$-in holes), with the lowest value for the smallest hole size. Data fitting using combined data of all hole sizes showed the average value of $C_{t}$ is 1.1 (Table 4). Since the value of $\mathrm{C}_{\mathrm{t}}$ remains near 1.1 for each hole diameter, it indicates that change of hole sizes does not have considerable effect on $C_{t}$; however, it does not mean that the error in all the cases was the same. Therefore, by adding around $10 \%$ of turbulent pressure losses to the Bingham predicted pressure, the errors of the model were eliminated, and the estimated total system pressures are close to the actual SPP (Fig. 5).

Water-based muds were used in $171 / 2$-in and $121 / 4$-in, 6 1/8-in/5 7/8-in boreholes, and oil-based muds (OBMs) were used in $81 / 2$-in borehole. Some practitioners hypothesize that hydraulics calculation errors in OBMs are greater than those in WBMs. As each borehole size was drilled with totally different parameters (such as depth and mud weight) from the others, any comparison between the OBMs and WBMs is not logical. Despite that, Table 4 compares the OBM in the

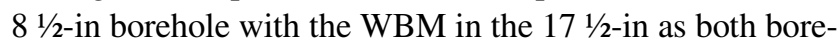
hole sizes have rather comparable mud weights. Based on this table, the average AAPE of the OBM is larger than that of the WBMs. It is noted that there is some hydraulics error in the 
Fig. 3 AAPEs of predicted total pressure drops from actual standpipe pressures for different cases in $8 \frac{1}{2}$-in hole. The optimized value of correction coefficient $\mathrm{C}_{\mathrm{t}}$ is 1.092 . The Power Law model has the worst performance (greatest error), whereas the Corrected Bingham model has the best performance (lowest error)
8 1/2-in Hole $\left(C_{t}=1.092\right)$

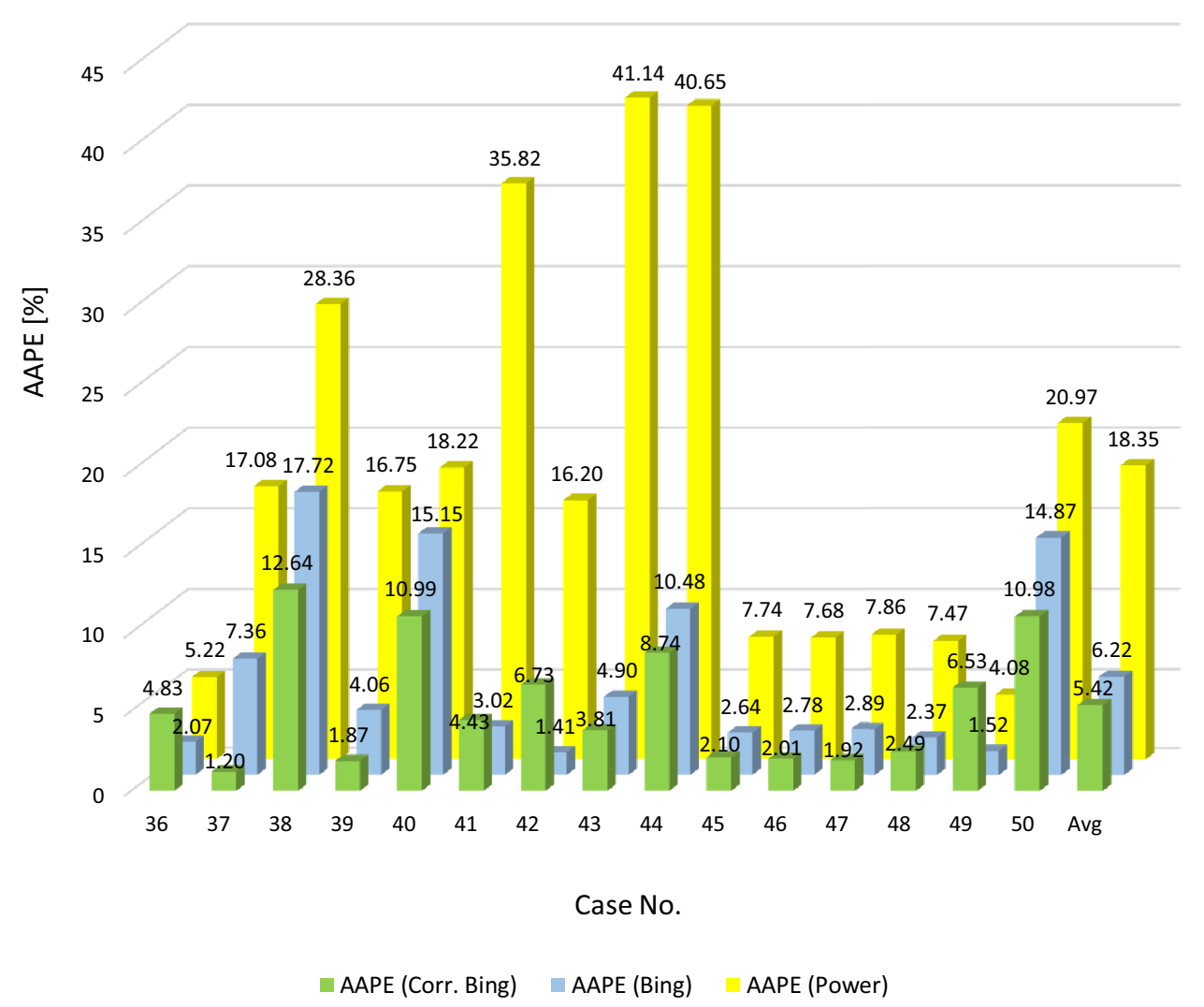

super-heavy WBMs (up to the mud weight of $20.7 \mathrm{ppg}$ ) used

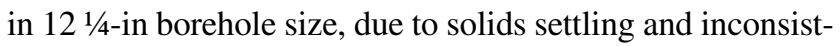
ent mud weight in the drill string and annulus. However, based on Table 4, since the value of $C_{t}$ is found to be consistent in different borehole sizes regardless of the drilling fluid type, the improvement due to the model in this study is independent of drilling fluid type.

The aforementioned table shows that the Corrected Bingham model showed the best performance of all with the lowest error in the considered hole sizes $(\mathrm{AAPE}=4.93$, MSE $=16,179$ ). This shows that the correction coefficient from this study has significantly improved the Bingham Plastic model's pressure estimation (AAPE $=7.65 \%$, MSE $=37,441)$. The Power Law model showed the lowest performance with the highest error $(\mathrm{AAPE}=12.83 \%$ and MSE $=64,411$ ).

\section{Other considerations}

For future works, two points should be considered. The first point is related to a possible error related to the pressure drop in the surface system (from the mud pumps through connection lines to the standpipe and swivel). Estimation of surface pressure drop using graphs given by Gabolde and Nguyen (2006) causes some error. Therefore, it is proposed that a pressure sensor is installed so that this pressure drop is measured rather than estimated. The second point is related to calibration of the hydraulic pressure drop estimations in the drill string. Therefore, it is proposed to use downhole pressure measurements in the measurement while drilling (MWD) system, which is a practice particularly in offshore operations. Using such a sensor, by changing the circulation flow rates, the effect on the drill string pressure drop measurements is found and compared with calculations.

\section{Conclusions and future work}

The followings are summary of the conclusions drawn from this study:

1. The proposed method in this work (called the Corrected Bingham Plastic model) applies a correction coefficient to turbulent flow pressure drops with the aim of covering all sources of errors and eliminating or reducing the 
Fig. 4 AAPE of predicted total pressure drops from actual standpipe pressures for different cases in $61 / 8^{\prime \prime}$ and $57 / 8$-in boreholes. The optimized value of the correction coefficient $\mathrm{C}_{\mathrm{t}}$ is 1.085 . The Power Law model has the worst performance (greatest error), whereas the Corrected Bingham model has the best performance (lowest error)

\section{1/8 \& 5 7/8-in Holes Hole $\left(C_{t}=1.085\right)$}

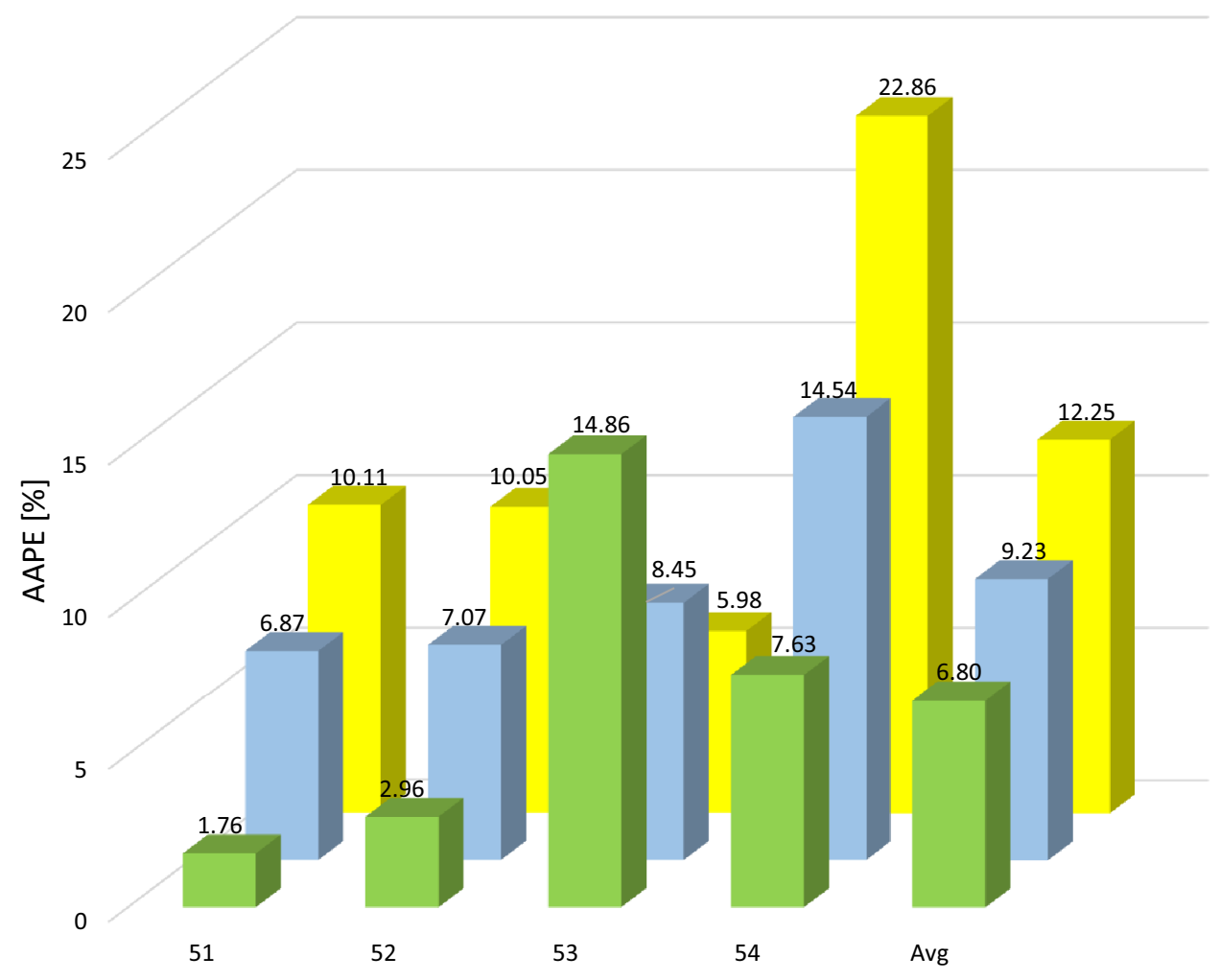

Case No.

$\square$ AAPE (Corr. Bing) $\square$ AAPE (Bing) $\quad$ AAPE (Power)

Table 4 MSE, AAPE, and the optimized values of the correction coefficient, $\mathrm{C}_{\mathrm{t}}$ in different borehole sizes

\begin{tabular}{|c|c|c|c|c|c|c|}
\hline & & \multicolumn{5}{|l|}{ Hole size } \\
\hline & & $17 \frac{1}{2}$ in & $12 \frac{1 / 4}{4}$ & $81 / 2$ in & $61 / 8$ in and $57 / 8$ in & All \\
\hline & & $\begin{array}{l}\text { WBM }(\mathrm{MW}=9.4- \\
13.6 \mathrm{ppg})\end{array}$ & $\begin{array}{l}\text { WBM }(\mathrm{MW}=12.5- \\
20.7 \mathrm{ppg})\end{array}$ & $\begin{array}{l}\text { OBM }(\mathrm{MW}=8.82- \\
10.6 \mathrm{ppg})\end{array}$ & $\begin{array}{l}\text { WBM }(\mathrm{MW}=8-18.6 \\
\text { ppg })\end{array}$ & - \\
\hline \multirow{4}{*}{$\begin{array}{l}\mathrm{C}_{\mathrm{t}}(\text { for Corr. Bing }) \\
\text { AAPE [\%] }\end{array}$} & & 1.094 & 1.123 & 1.092 & 1.085 & 1.1 \\
\hline & Corr. Bingham & 3.5 & 4.75 & 5.42 & 6.8 & 4.93 \\
\hline & Bingham & 5.99 & 9.64 & 6.22 & 9.23 & 7.65 \\
\hline & Power Law & 6.87 & 13.28 & 18.35 & 12.25 & 12.83 \\
\hline
\end{tabular}

WBM and OBM stand for water-based mud and oil-based mud, respectively. As each borehole size was drilled with totally different parameters from the others, a logical comparison between the OBMs and WBMs is not possible. Despite that, comparing the OBM in the $81 \frac{1}{2}$-in borehole with the WBM in the $171 / 2$-in (as both borehole sizes have rather comparable mud weights), the average AAPE of the OBM is larger than that of the WBMs. It is noted that there should be some hydraulics error in the super-heavy WBMs (up to 20.7 ppg mud weight)

discrepancy between pressures estimated by the Bingham Plastic model and actual standpipe pressures.

2. Using field measurements, optimized values of the correction coefficient $\left(\mathrm{C}_{\mathrm{t}}\right)$ were found to range from 1.08 to 1.12 in different borehole sizes of one of the fields in Iran. The value of 1.1 was found using the combined data of all borehole sizes. As this value is close to values of each borehole, it indicates that different geometries of borehole sizes do not have a considerable effect on $\mathrm{C}_{\mathrm{t}}$. On average, by adding around $10 \%$ of turbulent pressure losses, the errors of the Bingham model are eliminated, and the 
Fig. 5 Estimated total system pressure drop versus actual standpipe pressure using the Power Law, Bingham Plastic, and Corrected Bingham model

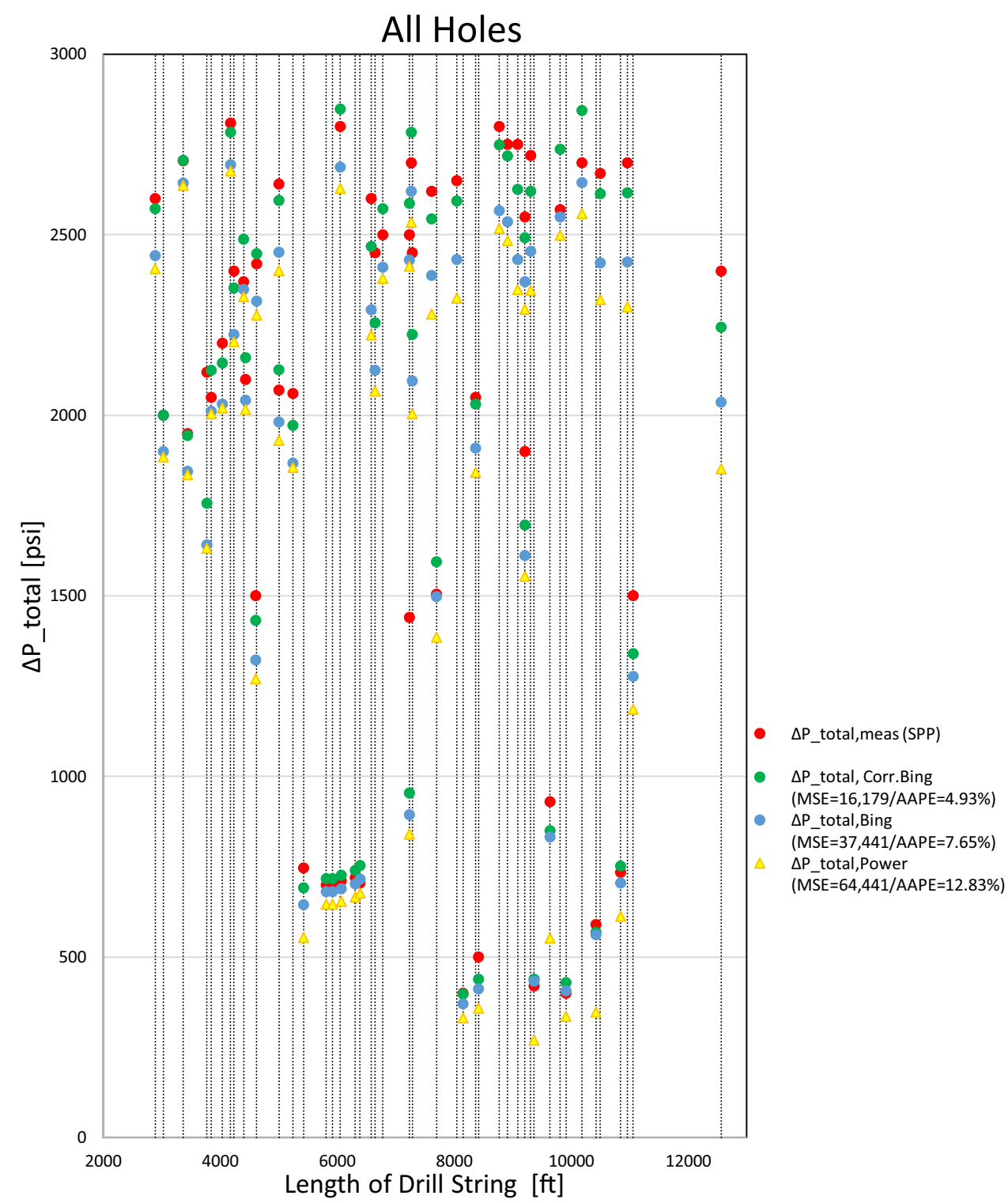

estimated total system pressures would be almost equal to actual standpipe pressure.

3. Results showed that the Corrected Bingham model showed the greatest accuracy/lowest error of all (average absolute percent error (AAPE) of $4.93 \%$ and mean square error (MSE) of 16,179). Results also show that this model's improvement is independent of the type of mud.

4. Placing the estimated system pressure calculated by the Corrected Bingham model as a display parameter at the rig-site mud logging data can complement measured standpipe pressure to detect and identify pressure-associated borehole problems And for application in managed pressure drilling (MPD). By using new filtered data during drilling, the correction coefficient can be empirically optimized in real time for each region.

5. This work presents a practical yet simple method in improving the accuracy of estimated hydraulics pressure drops. Therefore, accurate hydraulic estimations can contribute to comparison with the standpipe pressure and that can help us to detect hole problems.

6. As a future work, it is recommended that such data be gathered from different regions and similar data analysis be carried out in order to compare, refine, and better validate this model.

\section{Appendix}

Several researchers discussed using the Blasius equation to calculate the turbulent friction factor. Each researcher used their own coefficients (Rabia 1985; Moore 1986).

See Table 5. 
Table 5 Different coefficients of Blasius' equation for turbulent fanning friction factor " $\mathrm{f}$ " in terms of Reynolds number "Re" in different literature works

\begin{tabular}{lll}
\hline Rabia (1985) Moore (1986) & $\begin{array}{l}\text { Colebrook 1938, Kelessidis } \\
\text { et al. (2004), and Guo et al. } \\
\\
\end{array}$ \\
& $(2011)$
\end{tabular}

$f=0.057 \times R e^{-0.2} \quad f=0.046 \times R e^{-0.2} \quad f=0.079 \times R e^{-0.25}$

Acknowledgements The authors wish to thank Mr. Mark Enget for his constructive comments to improve the technical quality of the paper.

Funding The authors received no funding for this work.

\section{Declarations}

Conflict of interest There is no conflict of interests in this work.

Ethical approval All ethical matters have been regarded in this paper.

Open Access This article is licensed under a Creative Commons Attribution 4.0 International License, which permits use, sharing, adaptation, distribution and reproduction in any medium or format, as long as you give appropriate credit to the original author(s) and the source, provide a link to the Creative Commons licence, and indicate if changes were made. The images or other third party material in this article are included in the article's Creative Commons licence, unless indicated otherwise in a credit line to the material. If material is not included in the article's Creative Commons licence and your intended use is not permitted by statutory regulation or exceeds the permitted use, you will need to obtain permission directly from the copyright holder. To view a copy of this licence, visit http://creativecommons.org/licenses/by/4.0/.

\section{References}

API RP 13D, 2003 and 2009. Recommended practice on the rheology and hydraulics of oil-well drilling fluids. Fourth edition. American Petroleum Institute

Ashena R, Elmgerbi A, Rasouli G, A., Rabiei, M., Bahrami, A. (2020) Severe wellbore instability in a complex lithology formation necessitating casing while drilling and continuous circulation system. J Petrol Explor Prod Technol. https://doi.org/10.1007/ s13202-020-00834-3

Bailey WJ, Peden JM (2000) A generalized and consistent pressure drop and flow regime transition model for drilling hydraulics. SPE J Drill Completion 15:44-56

Blasius H (1913) Das Aehnlichkeitsgesetz bei Reibungsvorgangen in Flussigkeiten. VDL Forsch, 131-137

Bern PA, Morton K, Zamora M, May R, Moran DP, Hemphill T, Saasen A (2006). Modernization of the API recommended practice on rheology and hydraulics: creating easy access to integrated wellbore fluids engineering. SPE 98743-MS, Presented at IADC/ SPE Drilling Conference, 21-23 February, Miami, Florida, USA. doi: https://doi.org/10.2118/98743-MS

Bourgoyne AT, Millheim Jr KK, Chenevert ME, Young Jr FS (1991) Applied drilling engineering, SPE Textbook Series Vol. 2, ISBN: 978-1-55563-001-0

Calcada LA, Eler FM, Paraiso ECH, Scheid CM, Rocha DC (2012) Pressure drop in tool joints for the flow of water-based muds in oil well drilling. Braz J Petrol Gas, V. 6n.4, p. 145-157, ISSN 1982-0593

Churchill SW (1977) Friction factor equation spans all fluid-flow regimes. Chem Eng 7:91-92

Colebrook CF (1938) Turbulent flow in pipes, with particular reference to the transition region between the smooth and rough pipe laws. JICE 11:133-139

Denison E (1977) Pressure losses inside tool joints can alter drilling hydraulics. Presented at the energy technology conference and exhibitions, Houston, 18-22 September

Eckel JT, Bielstein WJ (1951) Nozzle design and the effect on drilling rate and pump operations. API Drilling and Production Practices, p. $28-46$

Fruhwirth RK, Thonhauser G, Mathis W (2006) Hybrid simulation using neural networks to predict drilling hydraulics in real time. SPE 103217-MS, presented at SPE annual technical conference and exhibition, San Antonio, Texas, USA, 24-27 September. doi: https://doi.org/10.2118/103217-MS

Gabolde G, Nguyen J (2006) Drilling data handbook. ISBN: Editions Technip. ISBM: 9782710809715

Guo B, Sun K, Ghalambor A, Xu C (2004) A closed form hydraulics equation for aerated mud drilling in inclined wells. SPE Drill Completion J 19(2):72-81

Guo B, Liu G (2011) Applied drilling circulation systems, Gulf Professional Publishing

Haciislamoglu M (1994) Practical pressure loss predictions in realistic annular geometries. SPE 28304-MS, presented at SPE annual technical conference and exhibition, 25-28 September, New Orleans, Louisiana. doi: https://doi.org/10.2118/28304-MS

Hemphill T, Ravi K (2005) Calculation of drill pipe rotation effects on axial flow: an engineering approach. SPE 97158-MS, presented at SPE annual technical conference and exhibition, 9-12 October, Dallas, Texas. doi: https://doi.org/10.2118/97158-MS

Hemphill T, Ravi K, Bern PA, Rojas J (2008) A simplified method for prediction of ECD increase with Drillpipe rotation. SPE 115378MS, presented at SPE annual technical conference and exhibition, 21-24 September, Denver, Colorado, USA. doi: https://doi.org/ 10.2118/115378-MS

Jeong Y, Shah S (2004) Analysis of tool joint effects for accurate friction pressure loss calculations. In: IADC/SPE Drilling Conference, Paper SPE 87182- MS, Dallas, Texas. doi: https://doi.org/ 10.2118/87182-MS

Kelessidis VC, Bandelis GE (2004) Flow patterns and minimum suspension velocity for efficient cuttings transport in horizontal and deviated wells in coiled-tubing drilling. SPE 81746-PA, Published in SPE Drilling and Completion Journal, Vol. 19 (04). doi: https:// doi.org/10.2118/81746-PA

Klotz JA, Brigham WE (1998) To determine Herschel-Bulkley coefficients. J Pet Technol (JPT) 50:80-81. https://doi.org/10.2118/ 52527-JPT

Kristler AW (1953) the effect of back pressure on 'Nozzle characteristics, a thesis submitted to the faculty in partial fulfillment of the requirements for the degree of Master of Science in mechanical engineering in the Rice Institute, Houston, Texas, USA

Luo Y, Peden JM (1987) Flow of drilling fluids through eccentric annuli. SPE 16692-MS, presented at SPE annual technical conference and exhibition, 27-30 Sep., Dallas, Texas, USA. doi: https:// doi.org/10.2118/16692-MS

McCain RC (1994) Pressure Loss in Tool Joint. Texas: Mobil, Dallas MI Drilling Fluids Co., 1991. Drilling Fluid Engineering Manual, Chapter 12, p. 13.

Moore PL (1986) Drilling practices manual. Second Edition, Published by PennWell Publishing Company

Ochoa MV (2006) Analysis of drilling fluid rheology and tool joint effect to reduce errors in hydraulics calculations. Submitted to the Office of Graduate Studies of Texas A\&M University in partial

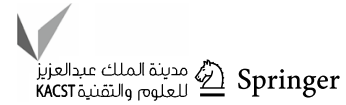


fulfillment of the requirements for the degree of Doctor of Philosophy, Texas A\&M University, USA

Ooms G, Burgerscentrum JM, Kampman-Reinhartz BE (1999) Influence of Drillpipe rotation and eccentricity on pressure drop over borehole during drilling. SPE 56638-MS, Presented at SPE annual technical conference and exhibition, 3-6 October, Houston, Texas. doi: https://doi.org/10.2118/56638-MS

Osisanya SO, Harris OO (2005) Evaluation of equivalent circulating density of drilling fluids under high pressure/high temperature conditions. SPE 97018-MS, presented at SPE annual technical conference and exhibition, 9-12 October, Dallas, Texas. doi: https://doi.org/10.2118/97018-MS

Patel A, Chaudhari R (2014) Optimization of Well hydraulics for riserless deepwater drilling operations under high temperature and high pressure environment. SPE 172304-MS, presented at SPE annual Caspian technical conference and exhibition, 12-14 November, Astana, Kazakhstan. doi: https://doi.org/10.2118/ 172304-MS

PowerD, Zamora M (2003) Drilling fluid yield stress: measurement techniques for improved understanding of critical drilling fluid parameters, paper aade-03-ntce-35 presented at the 2003 AADE technical conference, Houston, 1-3 April

Rabia H (1985) Oilwell drilling engineering. Published by Graham and Trotman, Principles and Practices

Ravi k, Hemphill T (2006) pipe Rotation and hole cleaning in eccentric annulus. SPE 99150-MS, Presented at IADC/SPE drilling conference, 21-23 February, Miami, Florida, USA. doi: https://doi.org/ 10.2118/99150-MS

Rommetveit, R., \& Bjorkevoll, K. S., 1997. Temperature and Pressure Effects on Drilling Fluid Rheology and ECD in Very Deep Wells. SPE 39282-MS, Presented at SPE/IADC Middle East Drilling Technology Conference, 23-25 November, Bahrain. doi: https:// doi.org/10.2118/39282-MS.

Schlumberger (1984) Cementing technology. Dowell Schlumberger Publications

Schlumberger, 2005. The oilfield glossary: where the oil field meets the dictionary, Available at: http//glossary.oilfield.slb.com/ (accessed in July 2020)

Shahri M, Kutlu B, Thetford T, Nelson B, Wilson T, Behounek M, Ashok P (2018) Presented at SPE liquids-rich basins conference
- North America, 5-6 September, Midland, Texas, USA. doi: https://doi.org/10.2118/191797-MS

Simões SQ (2005) The effect of tool joints on ECD while drilling with power law fluids. Master's Dissertation, University of Tulsa, Oklahoma, USA

Sun K, Guo B, Ghalambor A (2006) An analytical solution for aerated mud and foam drilling hydraulics in deviated holes. J Can Petrol Technol 45(3):23-27

Ugochukwu O (2015) Optimizing hydraulics for drilling operations. In: Paper presented at the SPE Nigeria Annual International Conference and Exhibition, Lagos, Nigeria, August. https://doi.org/10. 2118/178478-MS

Walker RE, Al-Rawi O (1970) Helical flow of bentonite slurries. SPE 3108 , Presented at fall meeting of the society of petroleum engineers of AIME, 4-7 October, Houston, Texas. doi: https://doi.org/ 10.2118/3108-MS

Wang Y, Salehi S (2015) Drilling hydraulics optimization using neural networks. SPE 173420-MS, Presented at SPE digital energy conference and exhibition, The Woodlands, Texas, USA, 3-5 March. doi: https://doi.org/10.2118/173420-MS

Weltmann RN (1956) Friction factors for flow of non-Newtonian materials in pipelines. Ind and Eng Chem 48(3):386-387

White WW, Zamora M, Svoboda CF (1996) Downhole measurements of synthetic based drilling fluid in offshore well quantify dynamic pressure and temperature distributions. SPE 35057-MS, Presented at IADC/SPE Drilling Conference, 12-15 March, New Orleans, Louisiana. Vol. 12 (3), p. 149. doi: https://doi.org/10. 2118/35057-MS

Zamora M, Roy S, Slater K (2005) Comparing a basic set of drilling fluid pressure loss relationships to flow-loop and field data. AADE National Technical Conference and Exhibition

Zoellner P, Thonhauser G, Lueftenegger M, Spoerker HF (2011) Automated real-time drilling hydraulics monitoring. SPE 140298-MS, presented at SPE/IADC drilling conference and exhibition, 1-3 March, Amsterdam, The Netherlands. doi: https://doi.org/10.2118/ 140298-MS

Publisher's Note Springer Nature remains neutral with regard to jurisdictional claims in published maps and institutional affiliations. 